\title{
DOCUMENTO
}

\section{Desafíos y Problemas de la educación jesuita}

\section{Adolfo Nicolás, S.I.'}

Discurso al comienzo de la celebración de los 150 años de la labor educativa de la Compañía de Jesús en Filipinas, Manila, 20 de julio 2009.²

\section{Introducción}

(1) Encantado de estar con vosotros esta mañana, mientras celebramos juntos el don de los ciento cincuenta años de educación jesuita en Filipinas. ¡Es mucho por lo que tenemos que estar agradecidos! Ha habido un crecimiento maravilloso, desde aquel diminuto Ateneo Municipal de 33 estudiantes, en 1859, hasta las nueve instituciones que ahora integran La Asociación Educativa Jesuita y que ha educado a centenares de miles de estudiantes a lo largo de esos años. Hemos sido agraciados con estudiantes excelentes que verdaderamente han sido importantes, entre los cuales sólo necesito mencionar el más famoso de todos, vuestro héroe nacional, José Rizal; por medio de él y de otros muchos, la educación jesuita ha sido una fuerza para el bien de la nación. Y, por supuesto, no podemos menos de dar gracias por los muchos, excelentes y generosos jesuitas, colaboradores y compañeros, que han trabajado juntos a lo largo de este siglo y medio, de los cuales vosotros sois los representantes actuales. Juntos damos gracias al Señor; pero hoy me vais a permitir que comience felicitándoos y dándoos a todos las gracias en nombre de la universal Compañía.

(2) Pero me siento todavía más feliz porque habéis decidido celebrar este siglo y medio en la educación, no de una manera auto-complaciente, sino de una manera

\footnotetext{
' Adolfo Nicolás es el Prepósito General de la Compañía de Jesús (Roma).

${ }^{2}$ Original en inglés. Traducción de ANTONIO MALDONADO CoRREA, S.I.
} 
muy ignaciana: mirando hacia delante, y preguntándoos qué más podéis hacer para gloria de Dios y servicio de su pueblo. Los organizadores del Congreso de Educación Básica han diseñado un magnífico logotipo que expresa muy bellamente el espíritu de nuestra reunión de hoy. El logo que he contemplado muestra un barco, una nave marítima que avanza hacia delante a velas desplegadas -con unas velas que se asemejan a una paloma y a una llama. El barco, ciertamente, nos recuerda el viaje a través de los mares del primer grupo de misioneros españoles que volvieron a Filipinas en 1859. Pero es también un símbolo de todos vosotros juntos, trasladándoos a nuevas fronteras, impulsados por el fuego y el viento del Espíritu Santo.

(3) Este logotipo me dice a mí dos cosas importantes acerca del sector educativo de la Provincia Filipina. En primer lugar, que mira hacia delante y hacia fuera. El mundo ha cambiado en muchos e importantes aspectos desde que se publicó Características de la educación jesuita; ciertamente que ha cambiado desde que se elaboró por primera vez la Ratio Studiorum. Me agrada ver, por ejemplo, que más tarde en el programa el Presidente Tyler Sherwood hablará del hecho de que "nuestros estudiantes y la educación están evolucionando. ¿'Y nosotros?" En otras palabras, estáis cuestionándoos acerca de las nuevas necesidades, estáis buscando nuevas respuestas en un mundo nuevo.

(4) Pero la segunda cosa que este logotipo me dice a mí es que esta asamblea tiene que ser también un mirar hacia dentro. Hoy día se oye hablar mucho de la educación que es competitiva, en un ambiente pedagógico cambiante, y ciertamente esto es importante. Pero este logo me dice que a lo que apunta esta asamblea no es sólo a una puesta al día profesional, sino a un escuchar al Espíritu, dejando que el Espíritu sea realmente el viento que hinche las velas y dirija la nave de nuestros colegios. En otras palabras, entiendo que estos días están llamados a emplearse en un espíritu y una actitud discerniente y de escucha.

(5) Eso me da más confianza al hablar, porque sé que vosotros no vais a buscar que yo os dé respuestas hechas y completas, aun cuando me habéis dado un título tremendamente ambicioso: "¡Problemas y Desafíos en la Educación Jesuita!" Al fin de cuentas, vosotros sois los expertos en educación, y no yo. Vosotros habéis estado profundamente implicados en este apostolado durante mucho tiempo y conocéis mucho mejor que yo, creo, cuáles son los problemas y desafíos. Además, vosotros estáis familiarizados con muchos y excelentes documentos que todavía tienen mucho que decirnos: las Características de la Educación Jesuita, Paradigma Pedagógico Ignaciano, y la clásica conferencia del padre Arrupe, en 1973, Hombres para los demás. Así pues, mi contribución va ser más modesta. Es mi 
intención contribuir con unos cuantos pensamientos que provoque vuestro propio pensamiento, escucha e intercambio. De hecho, espero suscitar más interrogantes que dar respuestas; y no se trata de "preguntas capciosas", en el sentido de que yo posea ya las respuestas. A veces, las preguntas son medios con los que nos es dado crear resquicios, aperturas en las sólidas murallas de nuestra defensa, por los que penetre el soplo del Espíritu.

(6) ¡Mi experiencia, sin embargo, es que si realmente se intenta escuchar al Espíritu, uno termina en sitios extraños y sorprendentes! Así es como yo acabé, sin yo planificarlo ni preverlo, como General de la Compañía, el año pasado. De este modo espero que al final de este Congreso, os sentiréis sorprendidos de encontraros en tanto que individuos y colegios y como una red, jen maravillosos nuevos lugares! ¡Algunos de vosotros podéis encontraros en Roma (esto no es una amenaza)! Pero esa será la prueba, creo yo, del éxito de esta reunión: si al fin, vosotros os liberáis de algo a lo que habéis estado amarrados por razones de seguridad, y bogáis adelante un poco más lejos, un poco más profundamente.

\section{La cuestión fundamental}

(7) Una de las palabras favoritas de la Congregación general $35^{a}$, que ha cautivado la imaginación de tantos jesuitas y amigos en misión, es "fronteras". Muchos en la Iglesia, muchas otras congregaciones, la están usando también. No somos propietarios del término. Pero, esa palabra es una palabra muy evocadora. Se puede entender más fácilmente en su primitivo significado geográfico. Cuando los primeros jesuitas de la Provincia de Aragón se hicieron a la vela en la nave Luisita, hasta Manila, en 1859, en aquellos días en los que los viajes duraban más e implicaban más riesgos, obviamente aquel era un viaje a las fronteras. Ellos viajaban a un país muy lejos de su propio país, iy no podían usar el "Google Tierra", para obtener información o estadísticas, o para que les mostrase imágenes de su nuevo hogar! Hoy día, hay nuevos colegios jesuitas en lugares como Kosovo y Sudán, lugares donde todavía hay tanta necesidad, tales riesgos y tan grandes desafíos, que resulta fácil comprender que, al abrir estos colegios, hemos ido a las "fronteras".

(8) Pero, ¿̇qué puede deciros a vosotros la palabra "fronteras", cuando casi todos vosotros tenéis que ir, día tras día, al mismo campus, al mismo despacho, a la misma aula? ¿ Cuáles son las "fronteras" para un sistema educativo bien establecido, lleno de éxito, y respetado, como el que encontramos aquí en Filipinas? 
(9) Creo que la clave para entender la palabra "fronteras" está en volver a lo que el Santo Padre dijo cuando se dirigió a nosotros jesuitas, durante la reciente Congregación general $35^{a}$. Muchos de vosotros estáis muy familiarizados con este maravilloso discurso, cuando el papa Benedicto XVI nos dijo a nosotros, y por extensión, a todos vosotros: La lglesia os necesita, cuenta con vosotros, y sigue acudiendo a vosotros con confianza, particularmente a fin de llegar a aquellos lugares geográficos y espirituales a donde otros no llegan, o encuentran dificultad en llegar (alocución, $n^{\circ} 2$ ). "Los lugares geográficos y espirituales a donde otros no llegan, o encuentran difícil llegar": estos lugares son nuestras "fronteras".

(10) Como bien sabéis, nosotros en la educación jesuita, no tenemos metas pequeñas, sino un enorme ideal: ayudar a que nuestros estudiantes consigan lo que el $P$. Kolvenbach describió como el pleno crecimiento de la persona, que conduce a la acción, -acción inundada por el espíritu y la presencia de Jesucristo, el Hombrepara-los demás. ¿¿Cuáles son las fronteras a las que necesitamos "ir", en orden a lograr esta meta?

(11) Como he dicho, yo no tengo todas las respuestas a estas preguntas; $y$ creo que toda la intención de este Congreso es que todos nosotros, juntos, busquemos estas respuestas. Pero permitidme que comparta con vosotros algunas de mis propias reflexiones que podrían estimular vuestra propia reflexión. Fundamentalmente, desearía proponer dos fronteras. Ellas son las dos preocupaciones más importantes que tengo respecto a la Compañía de Jesús hoy día, y creo que son también preocupaciones para nuestra misión en la educación.

\section{La frontera de la profundidad}

(12) La primera frontera que desearía proponeros es la frontera de la profundidad.

Profundidad es, en mi opinión, quizás una mejor traducción del magis ignaciano. El inconveniente de traducir magis simplemente como más es que se puede entender con demasiada facilidad como el más de una cultura competitiva y consumista. Si tenemos más premios, calificaciones más altas, más ordenadores y más campos de deportes, más miembros de la Facultad con una alta graduación..., entonces podemos engañarnos con demasiada facilidad y creer que estamos viviendo el magis. No digo que estas cosas no sean importantes, ellas son vitales para un buen colegio. Pero para que sea un buen colegio jesuita, ellas no son suficientes. 
(13) Ignacio estaba siempre preocupado con la profundidad. Estoy seguro que vosotros habéis escuchado muchas veces aquel principio suyo Non multa, sed multum, literalmente, "No muchas cosas, sino mucho", originalmente una de las anotaciones en los Ejercicios Espirituales, pero aplicado con frecuencia también a la pedagogía ignaciana. Se podría glosar esto con estas palabras "no cantidad, sino profundidad": "lo que satisface al alma" dice lgnacio- en otras palabras, lo que realmente es importante, en el asunto de hacerse humano y cristiano- no son muchos trozos de conocimientos superficiales y de información, sino un profundo entender y apreciar lo que es más importante de todo.

(14) Cuando miramos a los Evangelios, vemos que Jesús siempre respondía en profundidad. Mirad cualquier escena de curación: la manera como Jesús cura al paralítico que sus amigos introducen por el tejado; el leproso; la mujer con el flujo de sangre. Jesús en primer lugar responde a una necesidad concreta e inmediata: la curación de una enfermedad. Pero seguidamente procede a responder a una necesidad más profunda: el peso de la culpabilidad o el sentimiento de desesperación, o el rechazo o el aislamiento. Finalmente se adentra más profundamente y ofrece lo que ellos ansían más intensamente, muchas veces sin saberlo: el don del reino de Dios, la amistad con un Dios de amor sin condiciones, de una manera que los transforma en lo más íntimo de sus personas.

(15) ¿Cuál es la profundidad de la educación que impartimos, y cómo podríamos sentirnos llamados a ir a más profundidad? Permitidme que os ofrezca unas cuantas preguntas que puedan expresar lo quiero decir.

(16) ¿Con cuánta profundidad respondemos a las necesidades de nuestros alumnos? Si nuestra enseñanza es buena y está actualizada, entonces respondemos a sus necesidades, formando y desarrollando sus talentos. Pero más allá de eso, hay otras necesidades más profundas. Incluso los más brillantes y mejor dotados de nuestros alumnos, están luchando. Más allá de las luchas normales de la juventud, muchos de ellos luchan con familias rotas, pelean con problemas de soledad, incomprensión e inseguridad más profundas que sus mentes. Y, ¿̇cómo respondemos a sus más profundas ansias de significado y propósito, de fuerza y esperanza, que constituyen el Reino de Dios experimentado en sus vidas?

(17) Estos días, en la liturgia, hemos estado leyendo la historia de Jacob y su lucha con Dios. Su primera visión es consoladora, prometedora, llena de luz: él ve ángeles que suben y bajan por una escala al cielo. Pero su última visión es mucho más oscura y más misteriosa, porque es más profunda. Pelea con un extraño, que resulta ser Dios, y Jacob gana la lucha, pero termina cojeando, andando un 
poco como lo hizo lgnacio. Quizás esta debería ser la imagen de lo que nuestros estudiantes deberían acabar siendo: no salir de nuestros colegios derechos, altos, completamente confiados y seguros de sí mismos, sino más bien incluso cojeando un poco, porque ellos han peleado en profundidad.

(18) ¿Hasta qué nivel de profundidad les ayudamos a ver? Cuando se vive en Roma, uno entra en muchas iglesias hermosas, adornadas con espléndidas imágenes, frescos, estatuas, cuadros, vidrieras, y uno cae en la cuenta de que en épocas pasadas, éstas eran las imágenes que llenaban la imaginación de la gente. Eran imágenes que enseñaban a la gente a aspirar a un cierto modelo de humanidad. Pero nuestros jóvenes están creciendo en un mundo en el que los medios les invaden con otras brillantes imágenes, en las vallas de publicidad, en los sitios de la red, en las portadas de las revistas y en las pantallas de televisión. Se trata de imágenes que están llenas de promesas. Venden sueños que les insinúan que ellos se hacen más humanos cuando tienen los artilugios que se anuncian y se visten a la moda. Lo que estas imágenes hacen es ocultar el rostro de los pobres, y de los que sufren, y los hacen invisibles. ¿Cómo podemos ayudarles a que vean más profundamente, de modo que ellos puedan ver el rostro de la humanidad oculta del pobre de una manera que les mueva a querer servir desde la compasión?

(19) ¿̇Hasta qué grado de profundidad les invitamos a pensar? Nuestros estudiantes hoy día, como sabéis, están inundados de una inmensa cantidad de información que sigue entrando en nuestros hogares, en nuestros ordenadores, nuestras vidas. La ingente cantidad de información y la facilidad con la que se puede pasar de una página a otra, puede fomentar la superficialidad. ¿̇Hasta qué profundidad les ayudamos a seleccionar, digerir, conectar, tomar decisiones acerca de este diluvio de datos y los concomitantes (aunque camuflados) valores que les acompañan? Hay evidencia de que la capacidad de la gente para adquirir la comprensión y un sentido crítico, se han debilitado. Cuando miro alrededor y veo tanto fundamentalismo y fanatismo por todo el mundo, y los sufrimientos que este alejamiento de un pensar equilibrado ha producido, me pregunto, ¿̇no tendremos que pensar más creativamente sobre cómo podemos estar seguros de que nuestros alumnos aprenden a pensar profundamente?

(20) ¿ Hasta qué grado de profundidad formamos nosotros su personalidad interior, sus compromisos y convicciones, su fe y su fortaleza? Sois conscientes de con cuánta rapidez incluso una cultura religiosa como la de Filipinas se está secularizando y haciendo plural. Por todas partes se ofrecen a nuestros jóvenes más y más opciones, -no sólo opciones de sitios en la red, en internet, opciones de canales de televisión, o televisión por cable $\mathrm{u}$ opciones de tiendas en los grandes 
supermercados-, sino opciones de valores y creencias. Esto no es necesariamente algo malo, pero significa que no se puede esperar que las estructuras externas y las tradiciones por sí solas les vayan a apoyar en su fe cristiana, en sus creencias o valores. He trabajado con inmigrantes filipinos, y he visto con qué facilidad, en un ambiente diverso, ellos se han pasado a otros grupos. Cuando se debilitan los apoyos externos, entonces deben hacerse más fuertes los internos. Profundidad de pensamientoy, todavía más importante, profundidad de experiencia deben madurar en una profundidad de convicción, que sea capaz de permanecer pacífica y firme incluso en un mundo confuso y hostil.

(21) Al fin y al cabo, la prueba de si nuestra educación es una educación de profundidad, es si somos capaces de producir personas que puedan "decidir desde el interior", -lo cual es otra manera de decir que la prueba de nuestra educación, en tanto que educación jesuita, reside en si podemos producir personas de discernimiento. Cada vez más, las personas hacen opciones, no desde el dominio interno de la fe, la conciencia, los valores, la verdad, sino desde las voces seductoras que llegan de fuera, desde el provecho, la ganancia, la opinión pública, la conveniencia y la moda. La gente se hace cada vez más débil en el hábito de encontrar, en las profundidades del corazón, las respuestas a los difíciles interrogantes que surgen. Por otro lado, si miramos a los graduados, de los que estamos más orgullosos, como fruto del sistema educativo jesuita, creo que encontramos en ellos una cierta profundidad de percepción, pensamiento, compromiso y carácter, y el hábito de decidir desde el interior.

\section{La frontera de la universalidad}

(22) La segunda frontera que me gustaría proponerles es la frontera de la universalidad. Quizás conozcan una carta que escribí recientemente sobre el tema de la universalidad de nuestra vocación jesuita, inspirada en el espíritu de CG35. Hoy, creo que una frontera que desafía a la educación jesuita es la de ser una educación más universal, en el sentido ignaciano de extensión de pertenencia y amplitud de preocupación y responsabilidad.

(23) Una vez más, universalidad traduce magis, pero de una manera que desafía el modo competitivo con el que a veces traducimos magis simplemente como excelencia. Sin duda, nos esforzamos por la excelencia, pero a veces caemos en la trampa de medir la excelencia sólo si nos vemos a nosotros como mejores que algunos otros colegios dirigidos por otros grupos religiosos, o peor aún, mejor que otros colegios jesuitas. 
(24) Cuando viajo por el mundo, veo la violencia y el sufrimiento causado por una terrible estrechez del sentido de pertenencia y de la competitividad. Es una paradoja de la globalización que a la par que las tecnologías nos permiten crecer en conocimiento de los que están muy lejos de nosotros, al mismo tiempo hay un gran miedo del otro, del que es diferente, del que no pertenece a mi tribu, a mi raza, o a mi casta. Por culpa de sus miedos, la gente acaba viviendo en un mundo muy pequeño, y consideran a esos reinos diminutos como infrahumanos insignificantes, en el mejor de los casos, o como amenazas que deben ser eliminadas, en el peor de los casos. Y, me temo que si no tenemos cuidado, el prestigio que distingue a nuestros colegios, la fama del "sello jesuita" de educación, nos puede tentar a hacer de nuestros colegios una nueva pero con todo estrecha base de pertenencia, que usamos para distinguirnos y separarnos nosotros de los demás.

(25) Pero no hay nada de esta estrechez de pertenencia, en la visión de la vida, propia de lgnacio. Él fue siempre un hombre de grandes horizontes: le gustaba mirar a las estrellas, a la inmensidad del cielo que reflejaba el amor de Dios, universal y omni-incluyente. La preocupación de lgnacio fue siempre el "bien más universal"; él quería que los jesuitas estuvieran dispuestos a servir en cualquier parte donde haya esperanza de Gloria de Dios. Y reunió a su alrededor un grupo de hombres tan diversos, de diferentes lenguas, culturas, nacionalidades y personalidades, para formar un único grupo de amigos en el Señor, que van más allá de sus pequeñas diferencias, en su consagración común a la misma misión universal.

(26) La CG35 destacó todavía más esta universalidad ignaciana al señalar con cuánta urgencia se necesita en nuestro mundo una perspectiva universal, que nos permita ver más allá de nuestras estrechas preocupaciones, y trabajar con otros. A los grandes desafíos del mundo no puede darles respuesta una Provincia por sí sola, o una región sola, ni por los jesuitas solos. A los enormes desafíos de Filipinas y Asia, para cercarnos más a casa, no se les puede hacer frente por parte de un colegio solo, o por una sola universidad. Ellos necesitan la grandeza de miras y amplitud de espíritu que supera los pequeños sectarismos, de modo que podamos trabajar unos con otros, jesuitas y demás cooperadores y compañeros, todos juntos en misión.

(27) Más concretamente, ¿qué podría significar esta frontera de universalidad, para la educación jesuita en Filipinas?

(28) En primer lugar, nuestros estudiantes, como resultado del tiempo que están con nosotros, ¿̇acaban teniendo un sentido más amplio de pertenencia y responsabilidad mayor que las que puedan tener respecto a sus propias familias, su clase 
social, sus clanes? Mis antecesores, los padres Arrupe y Kolvenbach, hablaron estupendamente sobre la meta de la educación jesuita en tanto que formadora de hombres y mujeres para los demás y con los demás: hombres y mujeres cuyos corazones han sido universalizados y ampliados, hasta sentir esta compasión por el pobre y el que sufre, que no son miembros de su propia familia de carne y sangre, pero que son ahora parte de la más extensa familia humana.

(29) En segundo lugar, en lo que se refiere a los mismos colegios, ¿̇podemos escapar de nuestro estrecho sentido de pertenencia a este colegio particular? Me siento muy contento, por ejemplo, al ver que los nueve colegios jesuitas de Filipinas están reunidos aquí para participar en este Congreso. Conozco los pasos que han dado la Comisión de Educación Básica Jesuita, y más recientemente la Comisión de Educación Jesuita de Bachillerato, y cómo se han esforzado por promover este sentido más amplio de pertenencia y cooperación,-pero no sin resistencia también, ¡lo sé! Sería más consolador descubrir que este tipo de reuniones no es algo que acontece sólo una vez cada 150 años, sino que cada vez más, los colegios dejan de vivir en indiferencia entre sí, y en competición unos con otros, y más bien que tratan de solucionar juntos muchas preocupaciones que tienen en común.

(30) En tercer lugar, ¿̇podemos escapar de nuestro particular sistema escolar, y servir a los que están fuera del sistema jesuita en Filipinas? Nuestros colegios han sido favorecidos con recursos humanos, materiales, académicos y espirituales mucho más que otros, en una nación en la que la pobreza sigue siendo aplastante para tantos, y en la que una buena educación puede convertirse en el cauce más eficaz para salir de esta situación deshumanizante. ¿QQué más podemos hacer, por ejemplo, para servir, apoyar, mejorar otros muchos colegios en Filipinas? ¿los beneficios de la Educación Jesuita han de verse limitados a estos nueve colegios, o podemos pensar más creativamente sobre modos más dinámicos, con los cuales, a pesar de nuestro limitado personal, podemos compartir la herencia y los recursos de la educación jesuita con un grupo más amplio de personas, especialmente los pobres, de la manera que lo están haciendo, por ejemplo, los colegios de la red de Cristo Rey y Natividad, en Estados Unidos, o la red Fe y Alegría en Latinoamérica?

(31) En cuarto lugar, ¿̇podemos liberarnos de nuestra preocupación por Filipinas y empezar a pensar en cómo podemos servir más al más amplio mundo de Asia, a nuestro alrededor? Me alegra oír que hay mucho interés por China y deseos de intercambio con esa gran nación, en algunos de vuestros colegios: éste es un desarrollo muy positivo. Pero, ¿qué decir de las otras naciones más pobres y de las menos establecidas misiones jesuitas en el Este de Asia? ¿Puede el sistema educativo en Filipinas lanzarse a servir y compartir con Timor Este, Myanmar, 
Camboya, para mencionar sólo unos pocos lugares donde las necesidades de lo que vosotros podéis compartir son mayores?

\section{Fronteras de profundidad y universalidad frente a las universidades}

(32) Ahora me gustaría dirigir una palabra especial a los que están implicados en la educación superior y han venido a estar con nosotros esta mañana. Espero que lo que he dicho antes acerca de las fronteras de profundidad y universalidad sea aplicable también a vosotros. Pero me gustaría elaborar un poco más sobre lo que las fronteras de profundidad y universalidad podrían significar para las universidades jesuitas.

(33) En su visita a Estados Unidos, el Santo Padre usó una comparación muy llamativa para describir a la Iglesia. Dijo que la Iglesia es como una catedral adornada con vidrieras de colores. Cuando uno está dentro de la Iglesia, con la luz que brilla a través de ellas, las vidrieras aparecen gloriosas y hermosas. Pero si se las ve desde fuera, parecen oscuras y no muy atractivas. Y el Santo Padre dijo que en el mundo de hoy, por desgracia, son demasiadas las personas que permanecen fuera y ven sólo el pobre y poco atrayente exterior.

(34) Hace poco, mi Consejo y yo hemos estado reflexionando sobre esta realidad actual de la aparente falta de atractivo de la Iglesia en el mundo de hoy. Es un problema muy serio. He oído que una encuesta en Gran Bretaña revelaba que la mayoría de la gente entrevistada creía que la religión producía más daño que bien en el mundo. Esto, obviamente, no es lo mismo en todas partes, pero este tipo de actitud es cada vez más corriente en muchas partes del mundo, no solamente en Occidente, y esto debilita la capacidad de la Iglesia para ganarse un auditorio para el mensaje de vida y esperanza del Evangelio. Hemos estado buscando comprender las causas de esta aparente debilidad de la credibilidad de la lglesia, con la esperanza de descubrir cómo la Compañía de Jesús, en tanto que servidora de la Iglesia, puede ayudar.

(35) Las causas son complejas, y este no es el lugar para detenernos en ellas. Pero, una cosa que se destacó muy claramente, cuando estudiamos este problema desde la perspectiva de varios continentes es que hay dos grupos que especialmente sufren esa alienación: los intelectuales y la juventud. 
(36) Evidentemente, estos grupos están presentes en nuestras universidades. Y por eso, me parece muy claro que nuestras universidades pueden jugar un papel especial en la respuesta a este desafío actual que se presenta a la Iglesia. Y las universidades pueden responder precisamente con una penetración más audaz y creativa en las fronteras de la profundidad y la universalidad, precisamente como universidades.

(37) Quizás pueda explicarlo mejor refiriéndome a algunas ideas concretas sacadas de la reciente y riquísima encíclica del papa Benedicto XVI, Caritas in Veritate.

(38) En primer lugar, el Santo Padre, reflexionando sobre la doctrina del papa Pablo VI en la Populorum Progressio a la luz de nuestro mundo actual de interconexión, hace esta impresionante afirmación: la sociedad más global nos hace más cercanos, pero no más hermanos (CiV, 19). La razón, afirma él, puede comprender lo esencial de la igualdad de la gente, nuestras ciencias y tecnologías pueden ayudarnos a controlar nuestra convivencia ciudadana pero el sentimiento vivo y la convicción de que los demás son realmente mi familia, mis hermanos y hermanas, de los cuales soy responsable, sólo puede surgir de una cordial experiencia del amor paternal de Dios hacia todos. ¿̇Con cuánta profundidad llegamos a los jóvenes confiados a nosotros, de modo que a la par que les damos un rigoroso entrenamiento intelectual y profesional, vamos más adelante y les tocamos al nivel del corazón, para emplear las palabras del Santo Padre? (CiV, 20)

(39) En segundo lugar, el papa Benedicto cita a Pablo VI, que dijo con mucha verdad: El mundo está en dificultades por falta de pensar (CiV, 53). Es éste uno de los convencimientos del Santo Padre a través de toda su Encíclica: la actual crisis económica a nivel mundial y el prolongado sufrimiento de millones de personas, nos revela que muchas de nuestras soluciones no funcionan, y exigen nuevas soluciones basadas en una manera más profunda, más adecuada y más creativa de entender las muchas y complejas realidades de la vida humana y del mundo: negocios, economía, cultura, el papel del Estado y la política, el medio ambiente, la familia, la migración, las relaciones internacionales, y la cooperación, los derechos y deberes humanos, el mismo sentido de lo que significa ser humano. Aquí hay una clara llamada a la profundidad: ¿̇cómo pueden nuestras universidades, con todos los intelectuales, profesores e investigadores tan bien dotados y perfectamente preparados que hay en ellas, promover una aún más profunda reflexión e investigación, sobre estas áreas cruciales de las que depende la creación de un futuro mejor para el mundo? 
(40) Finalmente, en esta encíclica en la que el Santo Padre memorablemente describe la globalización como la explosión de una interdependencia global (CiV 33), no es sorprendente que él llame a un tipo similar de interdependencia y cooperación en busca de la verdad en el amor. En vista de la complejidad de las cuestiones, escribe el Papa, es obvio que las diferentes ciencias deben trabajar juntas a través de un ordenado intercambio interdisciplinar..., en un esfuerzo colaborador, consagrado al servicio de la humanidad (CiV 30, 31). ¿Cómo pueden nuestras universidades jesuitas, -la misma palabra "universidad" participa de la misma raíz que "universal" -, prestar atención a esta llamada práctica a la universalidad, escapando de los enclaves parroquiales de asignaturas, departamentos, universidades, en incluso naciones, para comprometerse a realizar este tipo de trabajo colaborador que es un servicio para el futuro de nuestras gentes y de nuestro mundo? ¿ Cómo podrán nuestras universidades jesuitas en Filipinas, por ejemplo, profundizar su compromiso con los muy prometedores, pero todavía frágiles esfuerzos colaboradores, por ejemplo, de AJCU-EAO?

(41) Si nuestras universidades pueden profundizar en la formación y el trabajo intelectual, y hacer más genuinamente colaborador y universal nuestro trabajo junto con otros, nuestras universidades estarán verdaderamente al servicio de la misión de la lglesia para el desarrollo humano integral, y al mismo tiempo, darán un testimonio convincente, en el mundo secularizado de hoy, de la presencia del amor y la verdad dadoras de vida, que actúan en la Iglesia.

\section{Conclusión: caminando hacia adelante en la esperanza}

(42) Os esperan muchas más conferencias, y estoy seguro de que os van a ofrecer muchas más cosas desafiantes, sobre las que reflexionar. Por tanto, en el espíritu de non multa, sed multum, yo os voy a dejar con estas dos fronteras que, como he dicho, son, en mi opinión, dos de las más importantes fronteras para toda la Compañía de Jesús en toda su vida y misión, en el día de hoy: profundidad y universalidad. Confío que más adelante tendréis tiempo para reflexionar más profundamente sobre lo que he dicho, en orden a confirmar, corregir, concretar.

(43) Sin embargo, antes de terminar, me gustaría compartir con vosotros una pequeña anécdota de la vida del padre Arrupe. Oí decir que uno de sus valiosos objetos personales era una foto que le había dedicado el primer hombre que pisó la Luna, el astronauta Neil Armstrong. Era una foto de la tierra tomada desde la luna, y el padre Arrupe la tenía sobre su mesa de trabajo. Se convirtió para él en 
un poderoso memento. Cuando se veía enfrentado a un problema muy exigente, él solía mirar la foto y se preguntaba: ¿¿Dónde está ltalia en esa foto? ${ }_{2}$ Puedo ver Roma? ¿Puedo ver Borgo Santo Spirito, 4 (que es la dirección de la Curia)? Ciertamente, él no podía ver Roma, ni Borgo Santo Spirito. Y se decía a sí mismo: Bien, si no puedo ver Borgo Santo Spirito, iquizás el problema que me preocupa aquí en Borgo Santo Spirito no sea tan grande, después de todo! Y se tranquilizaba.

(44) ¡Es una buena anécdota, pienso yo, para muchos de vosotros, profesores y administradores cuando tenéis que hacer frente a lo que parecen problemas muy pesados en vuestro trabajo! ¡Espero que lo recordéis, y os sirva de alivio! Lo importante de esta historia, sin embargo, no es trivializar los problemas, o pretender que no son reales. Se trata de ver las cosas desde una perspectiva más amplia.

(45) Más exactamente, creo que esta foto le ayudó al P. Arrupe a ver las cosas, -nuestro trabajo, nuestro servicio, los problemas y desafíos a los que tenemos que hacer frente-, desde la perspectiva más verdadera del infinitamente más importante punto de vista de Dios. Lo que hacemos, cómo planificamos y elegimos, importa muchísimo; pero algo más grande, -el plan universal de Dios de llevar vida, esperanza y gozo al mundo-, es lo que da a esos planes y elecciones específicas, su verdadera profundidad, valor y significado.

(46) Hasta cierto punto, eso es lo que he intentado hacer dentro de mis posibilidades, por medio de esta charla introductoria. No he hablado técnicamente como un educador. Sin embargo, al recordaros este tema de una educación que promueve profundidad y universalidad, os he estado hablando no de objetivos pedagógicos generales, sino de un servicio del Evangelio. Si soñamos con un sistema educativo que enseña a la gente a decidir desde el interior, desde lo profundo de sus corazones, y servir generosamente no sólo a una tribu, sino a una porción de la humanidad tan grande como se pueda, esto es debido a que estos eran los objetivos de Jesús, y la única razón por la que existen los colegios jesuitas, es para servir a la humanidad de acuerdo con la visión y el espíritu del Evangelio.

(47) Permitidme que lo exprese de otra manera. Hace poco, durante una intensa reunión de trabajo de mi Consejo General y yo, uno de los consejeros advirtió que estábamos usando una y otra vez, los mismos verbos: "pianificare, coordinare, organizzare": planificar, coordinar, organizar. Estos son verbos organizativos, muy importantes y necesarios para seguir adelante. Pero, aquella tarde, cuando celebramos la Eucaristía, el Evangelio del día nos mostraba a Jesús enviando a sus discípulos, y los verbos que él usaba eran muy diferentes: predicar el evangelio a los pobres, curar a los enfermos, limpiar leprosos, expulsar demonios, resucitar 
muertos. Todos éstos eran verbos de vida, verbos dadores de vida, lo cual prueba que la misión de Dios en Jesús, el asunto que le ocupa, es hacer que la vida fluya más abundantemente a la humanidad en todo lugar donde esté en falta o se vea impedida. Y el verdadero secreto de la misión está, no en desprenderse de los verbos organizativos, o de los verbos del Evangelio, sino en conseguir que de alguna manera hagamos que las actividades organizativas que tenemos que realizar sean expresiones de las acciones dadoras de vida del Evangelio. ¡Sí, planificamos, coordinamos, organizamos, -pero todo ello sólo a fin de que podamos predicar la buena noticia a los pobres, curar a los enfermos, liberar a los esclavizados, resucitar a los muertos!

(48) Creo que sucede lo mismo respecto a la educación jesuita. Usamos muchos verbos en el curso de nuestras vidas en los colegios: preparamos esquemas de lecciones, practicamos el servicio de las clases, asistimos a las reuniones de departamentos, escribimos ensayos, evaluamos y ponemos notas a nuestros estudiantes. Pero al reflexionar en profundidad y universalidad, nos estamos recordando a nosotros mismos que todas estas acciones sólo las realizamos a fin de poder ser de alguna manera instrumentos para compartir, aumentar y enriquecer la vida según los planes de Dios.

(49) Este pensamiento no sólo nos desafía sino que también nos da ánimos. Los problemas y desafíos son muchos, pero nos recuerdan que al fin y al cabo, somos servidores de la misión de Cristo, y como el padre Arrupe veía en su foto aquella, nosotros hacemos todo lo que podemos, pero al final, todo está en las manos de Dios. Por tanto, mientras continuáis vuestro Congreso, yo pido para que los desafíos no os abrumen, sino que vosotros les deis la bienvenida con gozo e ilusión, con optimismo y esperanza. Como todos aquellos primeros jesuitas que volvieron en 1859 , como todos los fundadores de vuestros respectivos colegios, que comenzaron sin mapas de carreteras ni anteproyectos ni garantías, sino con energía y convicción, que vosotros sigáis caminando hacia las fronteras con valentía, seguros de que estáis realizando una parte del trabajo dador de vida, propio de Dios. 